\title{
DOMAIN-DRIVEN DESIGN AND SOFT SYSTEMS METHODOLOGY AS A FRAMEWORK TO AVOID SOFTWARE CRISES
}

\author{
Author(s) / Auteur(s) : \\ Prof. Nikitas ASSIMAKOPOULOS \\ University of Piraeus, Hellenic Society for Systemic Studies (HSSS) \\ assinik@unipi.gr \\ Panagiotis PAPAIOANNOU \\ University of Piraeus, Hellenic Society for Systemic Studies (HSSS) \\ p.papaioannou@gmail.com
}

\begin{abstract}
Résumé :
Crisis is considered to be an issue concerning complex systems like societies, organizations or even families. It can be defined as the situation in which the system functions poorly, the causes of the dysfunction are not immediately identified and immediate decisions need to be made. The type and the duration of a crisis may require different kinds of decision making. In a long-term crisis, when system changes may be required, the active participation of the affected people may be more important than the power and dynamics of the leadership. Software crises, in their their contemporary form as oganizational maffunctions, can still affect the viability of any organization. In this contribution we highlight the systemic aspects of a crisis, the complexity behind that and the role of systemic methodologies to explore its root causes and to design effective interventions. Our focus is on modeling as a means to simplify the complexity of the regarded phenomena and to build a knowledge consensus among stakeholders. Domain-Driven Design comes from software as an approach to deal with complex projects. It is based on models exploration in a creative collaboration between domain practitioners and solution providers. SSM is an established methodology for dealing with wicked situations. It incorporates the use of models and, along with Domain-Driven Design and other systemic methodologies can be employed to develop a common perception of the situation and a common language between interested parties in a crisis situation.
\end{abstract}

Keywords / Mots-clés :

Software Crisis, Domain-Driven Design, Soft Systems methodology, DCSYM, Systemic Modeling

\section{INTRODUCTION}

Crisis in general refers to an unpredictable event that leads to an unstable and possibly dangerous situation which will affect the society, a group of people, an organization, or even an individual. Crises are considered to cause negative changes to the organization's objectives, especially when they occur abruptly with little or without warning.

The term comes from the Greek language in which its main meanings are (a) the ability to understand a situation (b) the action of evaluating something and (c) the dangerous unexpected event itself. Indeed, according to the common sense, in the case of a crisis as an unexpected dangerous situation we need to build understanding of the situation and to evaluate many facets of the situation as well as possible actions.

Although crises may take various forms, here we will be dealing with organizational crises and, more specifically, with crises involving information systems development and maintenance within organizations.

An organizational crisis can be defined as an event which is perceived by managers and stakeholders as highly salient, unexpected, and potentially disruptive. That event can threaten an organization's goals and have negative consequences for its relationships with stakeholders (Bundy, Pfarrer, Short \& Coombs, 2017). 
In the case of information systems we use the term "software crisis" to describe information technology (IT) projects that fail to meet customer's explicit or implicit expectations or end up with unreliable software, behind the schedule and over the budget.

\section{SOFTWARE CRISIS}

The term "Software Crisis" is in use since early 70s. It can be defined as "the claim that software development projects are always over budget, behind schedule and unreliable" (de Vasconcelos, Kimble, Carreteiro \& Rocha, 2017).

The reasons were the rapid increase of computer capabilities and the complexity of the problems along with the complexity of the software itself. The interaction between them in a positive feedback loop accelerated the phenomenon which emerged as the "software crisis". During this time there was not something like "software engineering" and when it appeared later it was considered as the solution to problem of software crisis. However, that crisis lasted much longer having deeper nature than crises in manufacturing industry and the absence of a relatively universal methodology indicates that the problem still exists (Zykov, 2016). Today we may face "local crises" while developing large scale software (Zykov, 2017).

A newer view for software crisis comes from Fitzgerald (2012) who introduces the term "Software Crisis 2.0 " as the "inability to produce software to leverage the absolutely staggering increase in the volume of data being generated". Indeed, the volume of data produced by commercial or banking transactions, interactions through social media or the Internet of Things (IOT) is really big and the technologies and applications which exploit them only recently started to emerge.

Besides the classic software crisis approach, a new aspect of such a crisis has arisen, Complex Systems Engineering (CSE) crisis. Jankowski (2017) describes how difficult success is in the case of complex systems. According to him, two deeply rooted reasons are: 1) there is not clear understanding of the principles that govern the system and 2) the goal of the project and its objectives and specifications (i.e. the scope) are not clearly understood. As we see, the causes are related to understanding the governing principles and the objectives and specifications.

Another aspect for crisis in software and information systems in general is the business-IT alignment issue. Business-IT Alignment (BITA) is the organizational situation in which the relationship between business and IT is optimized in order to maximize the values of IT for the organization (El-Mekawy, Rusu, Perjons, 2015). BITA is a dynamic state rather than a static one and need continuous attention by the managers (Abcouwer \& Smit, 2015). BITA and related practices and applications are gaining in importance between scientists and practitioners. Research has shown that organizations that succeed in aligning business strategies with their IT strategies can improve their business performance (ElMekawy et.al., 2015).

Beyond that approach, Abcouwer \& Smit (2015) argue that "an organization should focus on the BITA process towards preparing for uncertain futures". They elaborate on the BITA role in all four phases of the organization's "adaptive cycle of resilience" (Equilibrium, Crisis, New combinations, Entrepreneurship) and state that there is not a standard or global approach for achieving BITA in an organization. According to them, organizational crisis as "a situation in which an organization resides, where the traditional ways of problem solving are no longer applicable and the organization is aware of that'. Manages cannot predict when a crisis will occur and BITA is a means to avoid or to deal with crises when they come. 


\section{CRISES AND SYSTEMICS}

\section{The systemic nature of crises}

Through intuition we can perceive crisis as a characteristic of complex systems. Indeed a "hard" system, a mechanical system, a machine, does not face crises. It may be out of order but this is not called a crises. In contrary, a social system or, in general, a system consisting of purposeful agents may face crises and there are a lot of such examples in the history or in our everyday life. In these cases the whole system dysfunctions and negative consequences may affect the parts (subsystems or individuals) of the system. So, we speak about social crises, financial crises or even emotional crises. In this context, an interesting case is the crisis in a socio-technical system like information systems along with processes and the people working around them. Software crises referred previously is such an example.

One of the most cited definitions was given by Pearson \& Clair (1998):

"An organizational crisis is a low-probability, high-impact situation that is perceived by critical stakeholders to threaten the viability of the organization and that is subjectively experienced by these individuals as personally and socially threatening. Ambiguity of cause, effect, and means of resolution of the organizational crisis will lead to disillusionment or loss of psychic and shared meaning, as well as to the shattering of commonly held beliefs and values and individuals' basic assumptions. During the crisis, decision making is pressed by perceived time constraints and colored by cognitive limitations."

This definition incorporates a lot of features and references to complex systems and provides a basis for systems thinking and systemic approaches: organization, stakeholders, subjective perceptions, ambiguity of cause and effect, shared meaning, common beliefs and values, assumptions, cognitive limitations.

Bertels, Jacques \& Boman (2005) describe a complex system as a system with a large number of highly interconnected components that can interact in various ways. They use the well-known systemic principle, that "behavioral properties of complex systems are neither derivable nor directly linked to behavior of its individual components" but an emergent property of the system. They use it for risk and crisis management in complex systems employing cases and examples from industrial firms, in fact complex sociotechnical systems. They conclude that crises are an inherent property of complex systems and therefore they cannot be avoided.

Farmer et al. (2012) associate complex systems with the crises in economy and financial markets. They consider markets as complex evolving systems of coupled networks of interacting agents. The dynamics in models describing these systems inherently involve sudden changes of state and such a change appears as a crisis of the system. They identify as complex systems those made up of a large number of interacting elements including people, companies and countries and being probabilistic and not deterministic. In such a system, the interactions between individuals cause the emergent behavior at the aggregate level of the system while, the same time, the individuals are influenced by the behavior of the whole. Risks, instabilities and crises are considered as emergent behaviors of the system.

Bergström and Dekker (2014), studying organizations in crisis situations, describe resilience as an emergent system property stating that "the macro-behavior of the system emerges from microbehavior, but not through direct control".

Minati (2018) presents the concept of Quasi-Systemics, distinguishes between "first and second systemics" and recommends that we should pay attention to the confusion of systems and non-systems and to avoid reductionist simplification misunderstandings. In his example he refers to crises distinguishing them in those that have systemic nature and those with a non-systemic nature.

Ignatyev (2012) argues that "crisis is the property of complex systems". He introduces the term "maximum adaptability zone" and argues that a system (enterprise) must be within maximum adaptability zone in order to retain its sustainable development and existence in changes flow. $\mathrm{He}$ 
brings as an example the economic systems stating that crisis situation is immanent characteristic of such a complex system.

Cárdenas et al. (2018) refer to social crises and associate them with the increased complexity of the society. Their case is a fast-growing economy, considering society and economy as two interacting subsystems of a whole. They argue that the growing economy increases the complexity of a social system leading to different demands from the system itself. Studying the case of the crisis in Chile they note that increase in complexity and related social reactions can be interpreted as signals of a crisis. However, they suggest that it is necessary to look at the whole context since these manifestations can be either part of a larger crisis or isolated events.

\section{Systemic Approach to Crisis Management}

After having recognized the systemic nature of a crisis we are proceeding to find proper systemic solutions or interventions.

A crisis may create proper conditions and may facilitate the emergence of charismatic leadership (Shamir \& Howell, 2018). This is indeed a systemic phenomenon. However, from the systemic point of view, a long-term crisis may require system changes. In this case, the active participation of the affected people may be more important than the power and dynamics of the leadership.

Again Pearson \& Clair (1998) give the following comprehensive definition for crisis management:

"Effective crisis management involves minimizing potential risk before a triggering event. In response to a triggering event, effective crisis management involves improvising and interacting by key stakeholders so that individual and collective sense making, shared meaning, and roles are reconstructed. Following a triggering event, effective crisis management entails individual and organizational readjustment of basic assumptions, as well as behavioral and emotional responses aimed at recovery and readjustment".

As well as their crisis definition, the above definition also opens up scope for systemic approaches by referring to stakeholders' involvement, collective sense and share meaning.

The nature of a crisis requires different kinds of reaction and interventions. In the context of this study we deal with the systemic crises, that is, crises that occur due to the systemic nature of the organization or the social or economic or other system in which a crisis has occurred. Crisis like a natural disaster or an unexpected disaster in the organization's infrastructure are serious events which requires urgent response, high managerial skills or even leadership skills but they are out of the scope of this study. Crises as malfunctions of a system require more sophisticated actions, interventions that take into account the systemic nature of the problem and, in general, require broader stakeholders' participation. Broader participation needs merging perceptions and creating common understanding about the situation and about the new policies and actions that will be applied.

The systemic approach to managing problems or crises has been studied extensively and many approaches, methods, methodologies, models and tools have been proposed. Collaboration, communication and common understanding are common in a lot of them.

Probst, G., \& Bassi (2014) state that a problem is not a consequence of a single cause and a static state of the underlying system is not enough to find a solution. Instead they suggest a roadmap for systemic interventions which, among others, includes: seeing the problem as a system and defining its boundaries, exploring the dynamics of the system, using causal loop diagrams, identifying feedback loops and creating a common understanding of the functioning of the system.

The value of the knowledge sharing in a community-based approach has been presented in detail by Kaewkitipong, Chen \& Ractham (2016) although based mainly in social media communications and interactions. The value of knowledge sharing lies not only during the crisis events but also before and after them.

It is almost a principle that successful and sustainable interventions must have the acceptance of the stakeholders of the problematic situation. The value of stakeholders' involvement and participatory decision making has been explained extensively and a lot of work has been published. 
Voinov \& Bousquet (2010) studied extensively stakeholders' engagement, collaboration and participation to the designed solutions through the so called Participatory Modeling. The term refers to the stakeholders' engagement in the modelling process including both the public and decision-makers. According to Voinov \& Bousquet (2010) it incorporates various types of approaches each one closely related to particular researchers groups. Going further they present more stakeholder-based processes, related modeling tools as well as various types of stakeholder's involvement in modeling. They mention the common accepted fact that, since stakeholders will bear the consequences, they should participate to the design of the intervention and this will lead to successful implementations with fewer conflicts. Their study focus on environmental assessment but the concepts, methodologies and conclusions for collaborative design in a systemic context have quite broader applications. Newer developments on stakeholders' involvement include social media and web applications which change the context, scale and dynamics of stakeholders' participation (Voinov et al. 2016).

Pipek \& Kerne (2014), from the "Computer-Supported Cooperative Work" point of view, explains the benefits from participatory decision-making and participatory design not only in crisis situations but in "the context of the full disaster lifecycle - preparedness, warning, impact, response, recovery, and mitigation phases".

Lee (2016) focuses on systems thinking for wicked problems and considers disasters as wicked problems. She emphasizes the need for collaborative (democratic) design and decision making and, going further, she asserts "Design as Universal Human Right".

From the above we can conclude the following:

1) Systemic crises require systemic interventions

2) Stakeholders involvement is important in designing an intervention that causes systemic changes and affects people in a corporate or social organization.

3 ) It is important that all involved have a common perception of the problem

4) There is a need to create common accepted models for the problem and base the design, implementation and communications on these models.

\section{SYSTEMIC METHODOLOGIES OVERVIEW}

\section{Systemic Methodologies for Participatory Modeling and Design}

While all systemic methodologies, by their very nature, bring together different perspectives and encourage stakeholder involvement, the following methodologies offer specific benefits in the participative planning and design.

\section{Interactive Planning (IP)}

IP, proposed and diffused by Russel Ackoff (2001), is directed at creating the future (of the organization or the problematic situation) by designing a desirable present and by selecting interventions to close the gap between "now and then". It is based on all stakeholders' participation in the planning process securing their engagement and commitment to the intervention.

\section{Strategic Assumptions Surfacing and Testing (SAST)}

SAST is a systemic methodology for dealing with wicked situations and can be used to policy design and planning as a dialectical approach. Three of its principles (out of four) are related to stakeholders' participation: (a) Participation (a lot of stakeholders should be involved), (b) Adversarial positions of stakeholders and (c) Integrative (different options must be brought together). SAST can be employed to encourage and orientate a participative style in managing the problematic situation (Jackson, 2003).

\section{Viable System Model (VSM)}

Organizational cybernetics as developed by Stafford Beer, formulating the well-known Viable System Model (Beer (1979) are based on the concepts of the black box, negative feedback and variety. Viable 
System Model (VSM) represents a system that is known-to-be-viable and the viability of an organization should be examined in according to this model.

VSM offers an easy way to developing a common understanding of the organizational complexity and can provide the basis and a language for discussing issues related to organizational structure and operation, stability and change, control and co-ordination, centralization vs decentralization etc. (Jackson, 2003).

\section{Causal Loop Diagrams}

Causal Loop Diagrams (CLD) help to model the interdependencies of the various elements of a system whereas the system depicts the problematic situation. Simple models are well understood by all stakeholders and can be the basis for interactive collaboration with the policy makers. Their deeper value is that they allow looking beyond the mess presented in the surface of the problematic situation, discover the underlying patterns or feedback loops and determining the system behavior (Jackson, 2003).

\section{Soft Systems Methodology}

Soft Systems Methodology (SSM) (Checkland, 2000), (Jackson, 2003) is a methodology aimed at problem solving in soft systems in which the definition of the problem is a problem itself. Although not distinct, SSM consist of seven stages or phases. It can be used to bring order out of the mess and to provide a roadmap for stakeholders' collaboration. It incorporates some powerful approaches for modelling the problematic situation and the solution: (a) The rich picture (b) the CATWOE statement for creating the root definitions (Customers, Actors, Transformation, Worldview, Owner, and Environmental Constraints). Besides that, the SSM's conceptual models creation phase is an opportunity to apply other systemic methodologies, more specifically, methodologies for building consensus like IP, SAST, VSM and CLD. SSM is based on conceptual models (current and desirable situation), thus arising the need for modelling methodologies.

\section{Domain-Driven Design: the systemic aspect}

\section{Domain-Driven Design in brief}

Domain-Driven Design (DDD) comes from the software development field. It is a development approach intended for complex projects where complexity refers to the requirements as well as the interactions between designers, developers and users of the product. It was introduced by Eric Evans (2004) in his book of the same title. The idea is based on the following principles:

(a) Start focusing on the core domain and domain logic,

(b) Base the design on model(s) of the domain,

(c) Initiate a creative collaboration between technical and domain experts and

(d) Iteratively refine a conceptual model of the domain and the related problems.

DDD incorporates a lot of systemic aspects the first being the holistic approach to the project of the software product development.

A brief representation of the DDD approach, based in Pattern Language Overview (Evans, 2014) is sown in Figure 1. 


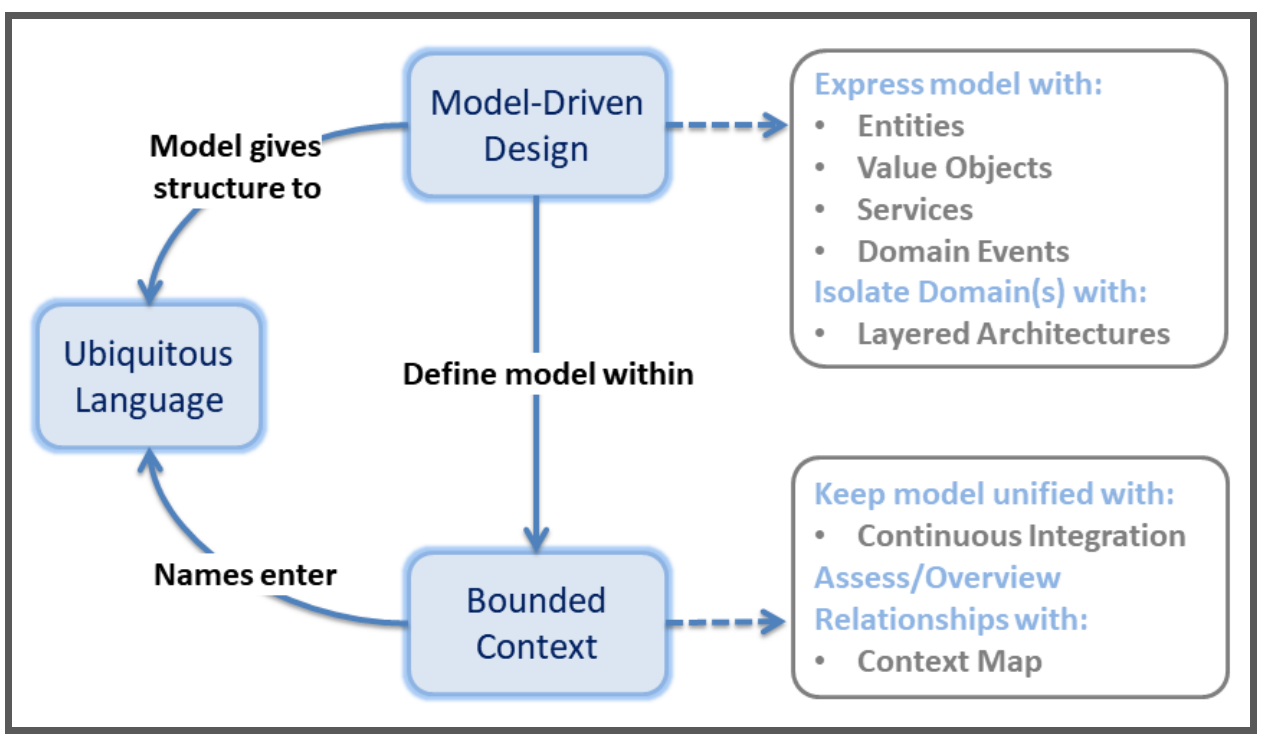

Figure 1. Domain-Driven Design at a glance

Referring to Figure 1, in the core of DDD there are three basic concepts:

- The concept of Model-Driven Design

- The Ubiquitous Language

- The Bounded Context

A model is an abstraction of the reality that includes selected aspects useful and required to understand the situation or the problem. In DDD a model describes aspects of the domain and is used to solve problems related to that domain. The concept of model-driven design is central in DDD and, actually, the whole DDD process is based on models.

Context refers to the background or situation or settings in which something happens or makes sense. We can say that all of them form a system with defined boundaries which, in DDD terminology, is the Bounded Context.

The Ubiquitous Language is the "global" language of the project. It is built around the domain model, within a specific bounded context and is used by all members of the team, both domain experts and technicians.

Model-driven design produces models that have meaning in a specific bounded context and these models provide the basis for structuring the Ubiquitous Language. The ubiquitous language is related to a particular bounded context from which it borrows the names it uses.

There are lots of supporting peripheral concepts connected with model-driven design and bounded context which diffuse the modelled perception throughout the whole project even to the code level. But the core of DDD, consisting of the four principles and the three basic concepts described previously, is a systemic paradigm that can have broader applications.

\section{Domain-Driven Design and Soft Systems Methodology}

SSM and DDD can be seen as serving the same purpose from different perspectives. SSM is strategicoriented while DDD is project oriented. However we can see similarities between them that help to employ both of them in a creative combination (Figure 2). 


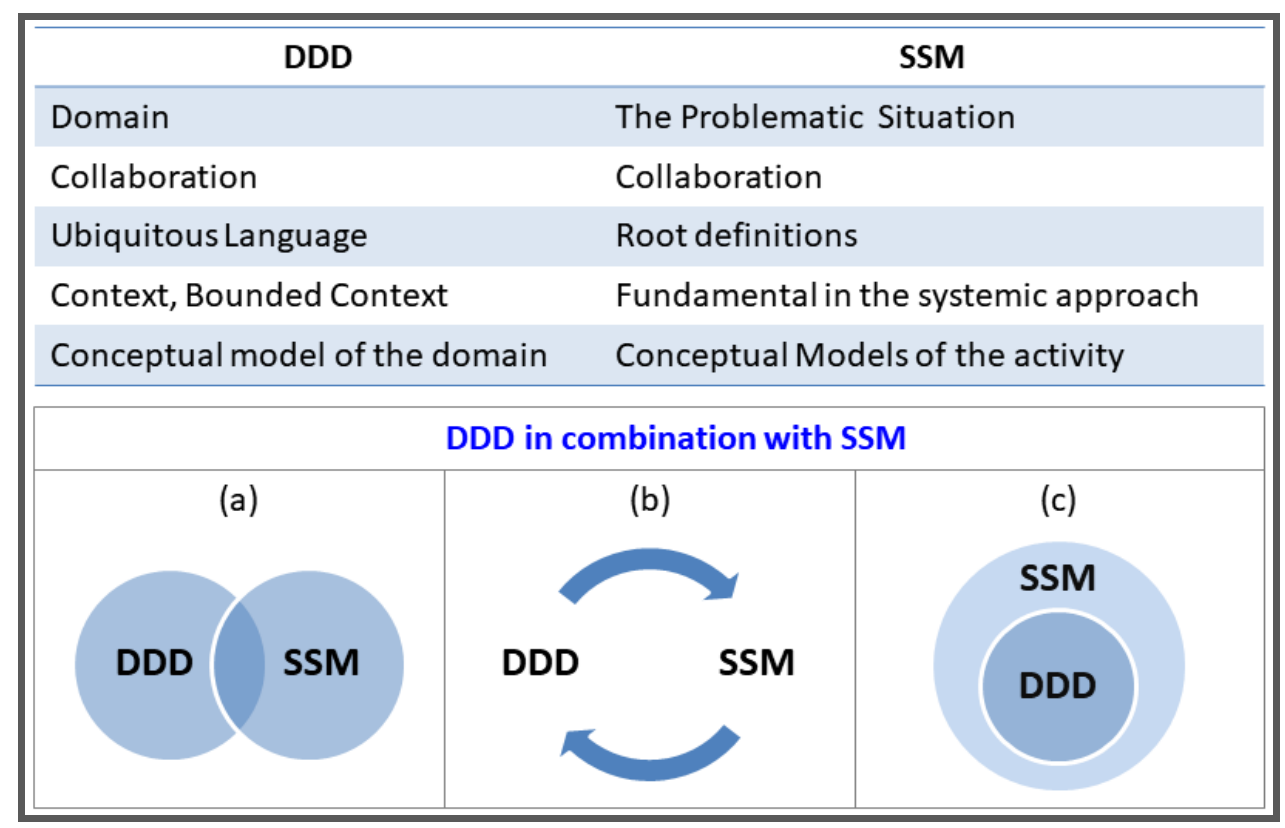

Figure 2. SSM in combination with DDD

The concept of Domain (DDD) can be associated with the problematic situation (SSM). The concept of collaboration is fundamental for both approaches. The Ubiquitous Language (DDD) can be related with the Root Definitions (SSM) while the (bounded) Context is fundamental in the systemic approach and, consequently, in SSM. Conceptual models of the domain (DDD) can be associated with conceptual models of the activity (SSM). These similarities allow easy combination of the two approaches for the purpose of having the benefits from both of them. A simple scenario could be to "run" both of them in "parallel" (terms are metaphorical) focusing on their common concepts (Figure 2, a). Another scenario could be the alternate use of the two methods (Figure 2, b) transferring results between them. The third case is to use SSM as a framework for DDD application (Figure 2, c).

\section{DCSYM for Systemic Modelling}

Design and Control Systemic Methodology (DCSYM) is a general purpose modelling approach dedicated to systems modelling (Assimakopoulos \& Theocharopoulos, 2009). It models the systemsubsystem hierarchy, the individual and the interactions between them. Interactions are classified as either "communication" or "control" and there is a qualitative characteristic on them based on the work of Bowen (1981). DCSYM employs diagrams aiming at effectively guiding a multi-agent dialectic process about boundary critiques, system structure, organizational procedures and interventions. It can be used as a conceptual modelling tool and its simplicity and generality make it suitable for use in a variety of application fields.

Both SSM and DDD rely on models. In a systemic approach we seek for a modelling approach that supports systemic aspects in creating conceptual models and is not dedicated or restricted to software development process. DCSYM is a methodology rather than a method and was created having systems in mind. It can be used to develop conceptual models for the problematic situation or for the intervention under design. As a modelling tool is a variety attenuator and can be used to facilitate the dialectic process between stakeholders. DCSYM by its nature supports participatory modelling

A comprehensive presentation of DCSYM is shown in Figure 3. 


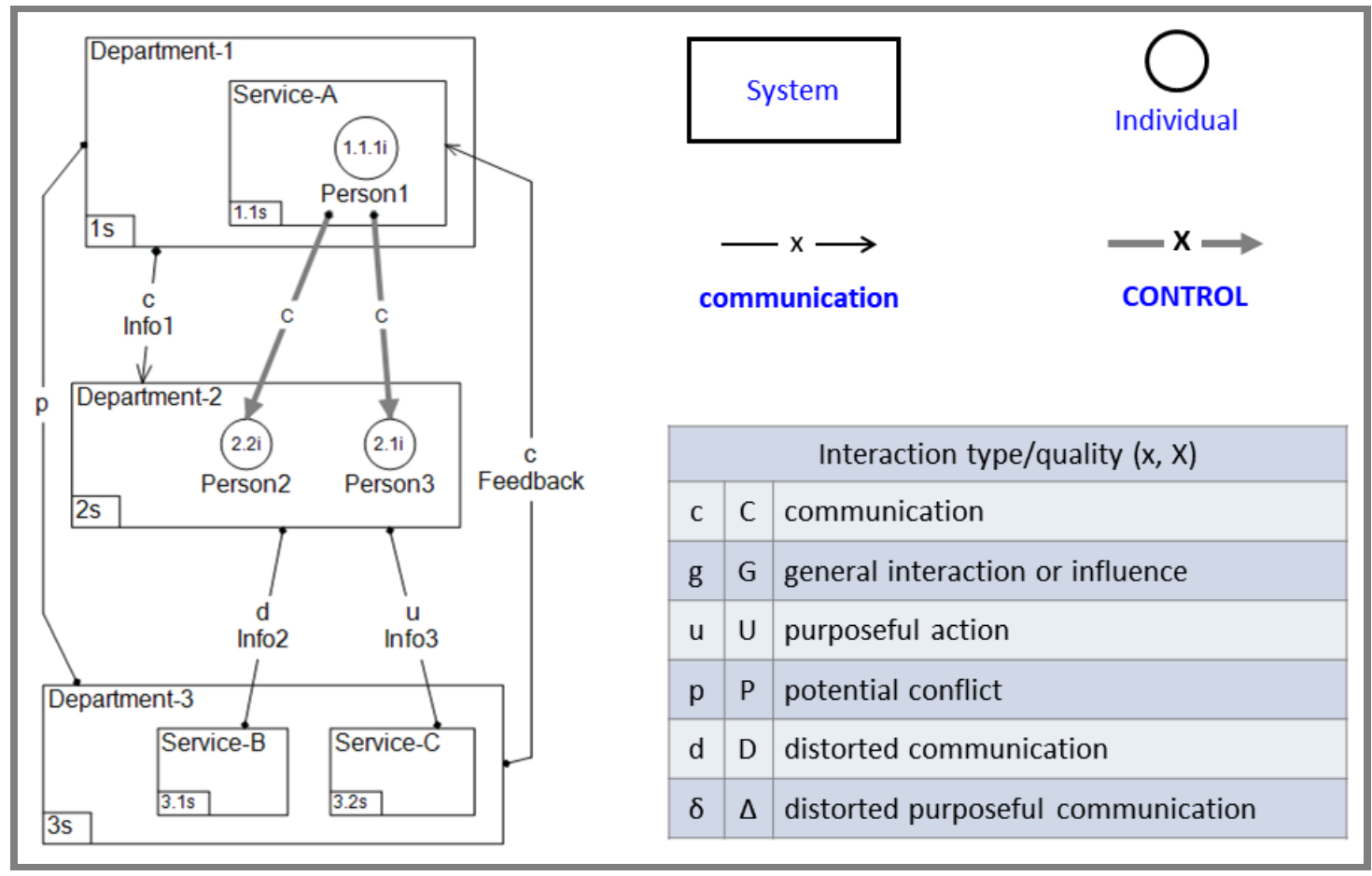

Figure 3. DCSYM at a glance

A system is depicted by a rectangle along with a label denoting the name of the system. A subsystem is a rectangle inside a rectangle. The individual is depicted by a circle with a label below that, again, denotes the name of the individual/role. Each element (system, subsystem, individual) is accompanied by a position number which depicts its nesting level within the system hierarchy. Interactions between the above elements are depicted by lines and can be directional or non-directional. They are classified as "communications", depicted by a thin line or as "controls" depicted by a thick line. The quality of the interaction is indicated by one of the symbols listed in the table in Figure 3 and placed on the corresponding line using a lowercase letter for communication and a capital letter for control.

\section{SYSTEMIC METHODOLOGIES FOR DEALING WITH CRISIS}

In crisis management literature three main stages are identified for the crises: prevention phase (precrisis), crisis event and corresponding crisis management and post-crisis phase related to outcomes and lessons learned.

Bundy et al. (2017), propose a framework for integrating crises and crisis management which is based on research in related fields. This framework classifies crises issues according to the stage and according to the perspective from either inside or outside of the organization. Internal perspective is focused on the internal dynamics whereas external is focused on managing external stakeholders. This framework can be summarized in a table in which the columns correspond to the three main stages of crisis management and the rows to the two perspectives: internal and external.

A "software crisis" involves both internal and external stakeholders, thus it can be seen either with external or internal perspective.

The summary of the framework, based on classification in Bundy et al. (2017), is depicted in Table 1. 
Table 1. A framework for crisis management

\begin{tabular}{|c|c|c|c|}
\hline & Pre-Crisis Prevention & Crisis Management & Post-Crisis Outcomes \\
\hline $\begin{array}{c}\text { External } \\
\text { Perspective }\end{array}$ & $\begin{array}{l}\text { Stakeholder } \\
\text { Relationships } \\
\text { - Positive } \\
\text { Relationships } \\
\text { - Negative } \\
\text { Relationships }\end{array}$ & $\begin{array}{l}\text { Stakeholder Perceptions } \\
\text { - Response strategies } \\
\text { - Crisis type } \\
\text { - Endowed positive eval. } \\
\text { - Stakeholder identific. } \\
\text { - Powerful stakeholders } \\
\text { - Crisis spillover }\end{array}$ & $\begin{array}{l}\text { Social } \\
\text { Evaluations } \\
\text { - Crisis response } \\
\text { strategies and social } \\
\text { evaluations }\end{array}$ \\
\hline $\begin{array}{c}\text { Internal } \\
\text { Perspective }\end{array}$ & $\begin{array}{l}\text { Organizational } \\
\text { Preparedness } \\
\text { - Organizing for } \\
\text { Reliability } \\
\text { - Organizational culture } \\
\text { and structure }\end{array}$ & $\begin{array}{c}\text { Crisis } \\
\text { Leadership }\end{array}$ & $\begin{array}{l}\text { Organizational } \\
\text { Learning } \\
\text { - The learning process } \\
\text { - Conditions on the } \\
\text { learning process } \\
\text { - Vicarious learning }\end{array}$ \\
\hline
\end{tabular}

Most of the topics in crisis management (Table 1) provide opportunities for systemic approach and all the previously referred systemic approaches can be selectively applied in the above stages of crisis management.

All the previously mentioned systemic methodologies can be used while crisis is in progress in the context of the "external perspective" in order to support "response strategies" to identify the "crisis type". In the context of the "internal perspective" and while crisis is in progress the main role is that of leadership and not that of participation. Although leadership is itself a systemic phenomenon, in this study we are dealing with "participative design", so we exclude the application of systemic methodologies in that phase.

SSM is an established methodology for wicked problems solving, especially for situations like the organizational crises related to software as described previously. SSM by its nature can support the process of change when the subject of change is under question. Thus, issues like "what we can do to improve reliability" or "what changes to organizational culture and structure should we do" can be addressed, designed and implemented by employing SSM. In the conceptual models creation phase, the so called $4^{\text {th }}$ phase, there is an opportunity to apply other systemic methodologies appropriate for building consensus between stakeholders through participative modelling.

DDD and SSM, although having different origins, share a lot of common concepts and they can be employed together when dealing with a "software crisis" (Figure 2). Other systemic methodologies can also be used in the SSM life cycle.

A map depicting the SSM cycle and points where DDD and the other systemic methodologies can be applied is shown in Figure 4. 


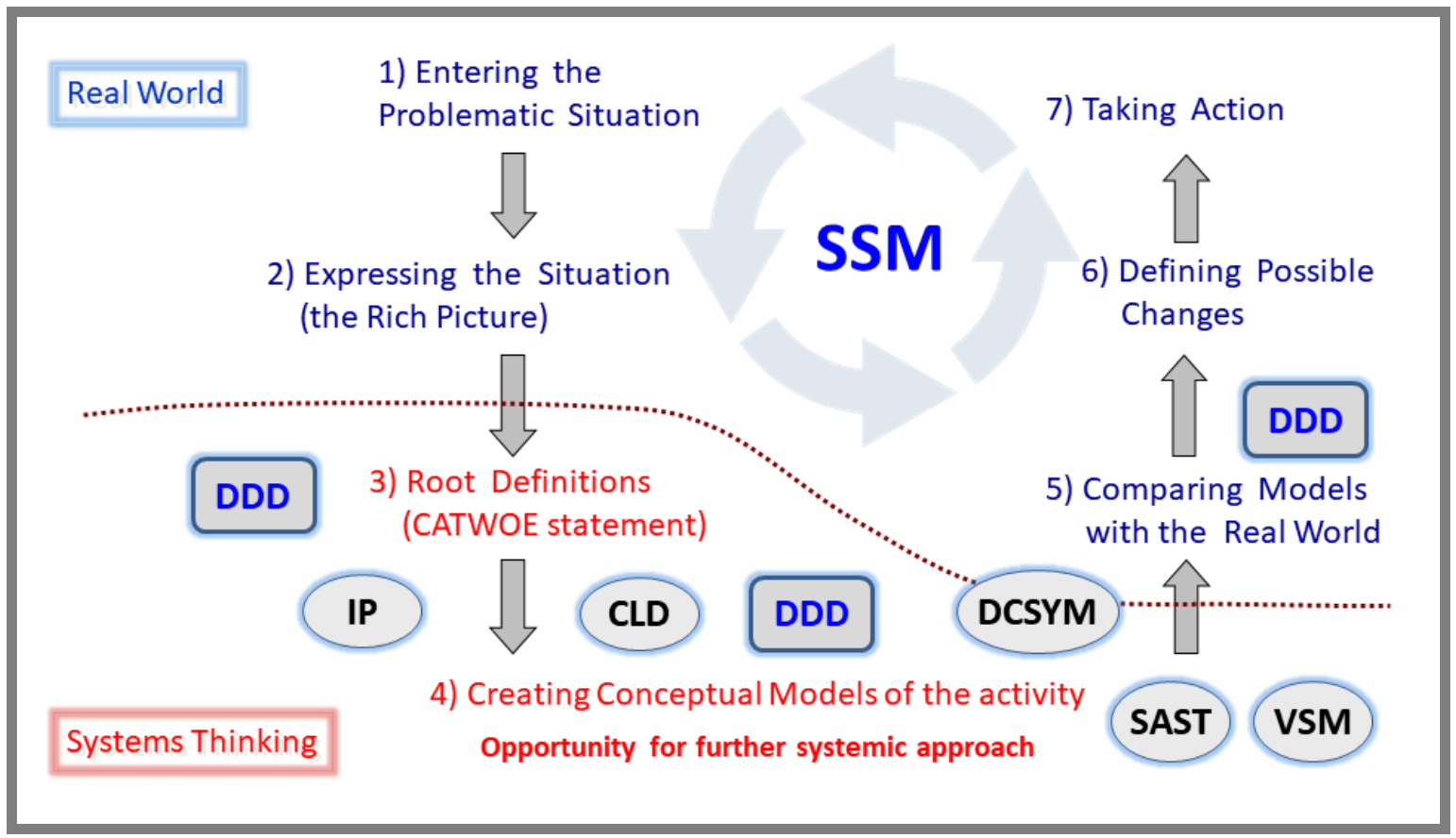

Figure 4. SSM enriched with DDD and other systemic methodologies

DDD is compatible with the use of models and introduces the Ubiquitous Language which takes meaning in a specific context. When describing situations the well-defined context i.e the bounded context is very important because it is what gives meaning to the models and the ubiquitous language. As a result different contexts may require different models and different languages. It can be important when dealing with different groups of people within the organization or with different stakeholders groups. These concepts are compatible with all systemic methodologies and can be used in combination with them.

Systemic methodologies like IP and SAST facilitate the stakeholders' participation as much as possible, help to reveal the tacit knowledge about the problem and enable the creation of a mutual understanding. IP works by creating the future designing a desirable present and it promotes and secures stakeholders engagement to the intervention. Thus, it can be employed when designing new policies or procedures towards "organizing for reliability" and/or "organizational culture and structure" in order to secure internal stakeholders participation. It could be also useful to maintain "positive relationships" with external stakeholders. SAST suggests that adversarial positions must be posed in order bring together the different options. Thus, it is very useful when dealing with negative stakeholders as a means to convert negative relationships into positive ones.

Organizational cybernetics and VSM can be extremely useful when assessing the reliability of the organization since viability implies reliability. It can be also used in designing "organizational culture and structure" because a "viable" organization incorporates a subsystem which sees towards the future, so, it is less likely to come into a crisis. Moreover, a system designed with VSM in mind supports much better the concept of "organizational learning" and the "learning process" after the crisis have passed.

Systemic modelling methodologies (CLD and DCSYM) can be used for modelling. They can facilitate the implementation of IP and SAST since they are based on stakeholders' participation and models can create a common language between them. Causal loop diagrams can reveal the causalities of complex situation and DCSYM can be used to create structural models of the problematic situation as well as the proposed improvements. 


\section{DISCUSSION AND CONCLUSION}

We studied how an organization can deal with a crisis situation related to IT systems and how it can overcome it. The proposed approach can be summarized as follows:

- SSM as a framework along with IP and SAST for participatory design

- DDD as a source of inspiration

- CLD and DCSYM for systemic modelling

Our study starts from crises in general but focuses on "software crises". The proposed approach can be applied in every type of crisis.

Bundy (2017), concludes that the cognitive capabilities of managers' and stakeholders' are reduced in a crisis. Since a significant part of our cognitive ability is based on crafted models and archetypes, a well-established background based on modelling will help in tough period of an emergency.

Specific methods for combining SM and DDD have already been proposed. Salahat \& Wade (2015 and 2019) propose a full framework for applying both DDD and SSM along with other concepts in problem solving.

A limitation of our study is that it has an exploratory orientation and has not been tested in action. Nevertheless, results and ideas from this study can serve as a basis for an improved conceptual model for further research.

We do believe that approaches based on modelling and interactive participation, have broader applications, beyond software engineering and, in this case, in pre-crisis or post-crisis management. Having built consensus, an organization will be ready for the next crisis whenever it occurs.

\section{RÉFÉRENCES}

Assimakopoulos, N., \& Theocharopoulos, I. (2009). "The Design and Control Systemic Methodology (DCSYM): a multi-agent modeling and operation platform". International Journal of Applied Systemic Studies, 2(3):193-217.

Abcouwer, T., \& Smit, B. (2015). "Business IT alignment: A never-ending story". Working Paper, UVA 2015.

Ackoff, R. L. (2001), "A brief guide to interactive planning and idealized design". Available at http://eaasos.info/Content/Downloads/AckoffGuidetoIdealizedRedesign.pdf. Retrived on September, 28, 2018.

Beer, S. (1979), The Heart of Enterprise, John Wiley \& Sons, Chichester

BERGSTRÖM, Johan; DEKKER, Sidney WA. "Bridging the macro and the micro by considering the meso: reflections on the fractal nature of resilience". Ecology and Society, 2014, 19.4.

Bertels, K., Jacques, J. M., \& Boman, M. (2005). "Risk and Crises Management in Complex Systems". Micro Meso Macro: Addressing Complex Systems Couplings, 305.

Bowen, K. (1981). "A conflict approach to the modelling of problems of and in organizations". Operational research, 81, 79-90.

Bundy, J., Pfarrer, M. D., Short, C. E., \& Coombs, W. T. (2017). "Crises and crisis management: Integration, interpretation, and research development". Journal of Management, 43(6), 1661-1692.

Cárdenas, J. P., Vidal, G., Urbina, C., Olivares, G., Rodrigo, P., \& Fuentes, M. (2018). Social Crises: Signatures of Complexity in a Fast-Growing Economy. Complexity, 2018.

Checkland, P. (2000). "Soft systems methodology: a thirty year retrospective". Systems research and behavioral science, 17(S1), S11-S58.

de Vasconcelos, J. B., Kimble, C., Carreteiro, P., \& Rocha, Á. (2017). "The application of knowledge management to software evolution". International Journal of Information Management, 37(1), 14991506. 
Dumas, M., La Rosa, M., Mendling, J., \& Reijers, H. A. (2013). Fundamentals of business process management (Vol. 1, p. 2). Springer, Heidelberg.

El-Mekawy, M., Rusu, L., \& Perjons, E. (2015). “An evaluation framework for comparing business-IT alignment models: A tool for supporting collaborative learning in organizations". Computers in Human Behavior, 51, 1229-1247.

Evans, E. (2004). Domain-driven design: tackling complexity in the heart of software. AddisonWesley Professional.

Evans, E. (2014). Domain-Driven Design Reference: Definitions and Pattern Summaries. Dog Ear Publishing.

Farmer, J. D., Gallegati, M., Hommes, C., Kirman, A., Ormerod, P., Cincotti, S.,\& Helbing, D. (2012). "A complex systems approach to constructing better models for managing financial markets and the economy". The European Physical Journal Special Topics, 214(1), 295-324.

Fitzgerald, B., "Software Crisis 2.0," IEEE Computer, vol. 45, no. 4, 2012, pp. 89-91.

Jackson, M. C. (2003). Systems thinking: Creative holism for managers (p. 378). Chichester: Wiley.

Jankowski, A. (2017). Interactive Granular Computations in Networks and Systems Engineering: A Practical Perspective. Springer International Publishing.

Kaewkitipong, L., Chen, C. C., \& Ractham, P. (2016). "A community-based approach to sharing knowledge before, during, and after crisis events: A case study from Thailand". Computers in Human Behavior, 54, 653-666.

Kirman, A. (2017). "The Economy as a Complex System". Economic Foundations for Social Complexity Science (pp. 1-16). Springer, Singapore.

Lee, A. J. (2016). "Systems Thinking”. In Resilience by Design(pp. 19-32). Springer, Cham.

Mikhail B. Ignatyev. "Crisis is the Property of Complex Systems". Journal of World Economic Research. Vol. 1, No. 1, 2012, pp. 1-5.

Minati, G. (2018). "The Non-Systemic Usages of Systems as Reductionism: Quasi-Systems and Quasi-Systemics". Systems, 6(3), 28.

Pearson, C. M., \& Clair, J. A. (1998). "Reframing crisis management". Academy of management review, 23(1), 59-76.

Pipek, V., Liu, S. B., \& Kerne, A. (2014). "Crisis informatics and collaboration: a brief introduction". Computer Supported Cooperative Work (CSCW), 23(4-6), 339-345.

Probst, G., \& Bassi, A. (2014). Tackling complexity: A systemic approach for decision makers. Sheffield, UK: Greenleaf Publishing

Salahat, M., \& Wade, S. (2009, March). "A Systems Thinking Approach to Domain-Driven Design". In UK Academy for Information Systems Conference Proceedings 2009 (p. 44).

Salahat, M. and S. Wade (2015). "Business Domain Modelling Using an Integrated Framework". World Academy of Science, Engineering and Technology organization conference, London,UK. 9(6)

Shamir, B., \& Howell, J. M. (2018). "Organizational and contextual influences on the emergence and effectiveness of charismatic leadership". In Leadership Now: Reflections on the Legacy of Boas Shamir (pp. 255-281). Emerald Publishing Limited.

Trichet, Jean-Claude, (2010) "Reflections on the Nature of Monetary Policy Non-Standard Measures and Finance Theory". Speech at the 6th ECB Central Banking Conference, Frankfurt, Germany, November 19, 2010

Voinov, A., \& Bousquet, F. (2010). "Modelling with stakeholders". Environmental Modelling \& Software, 25(11), 1268-1281.

Voinov, A., Kolagani, N., McCall, M. K., Glynn, P. D., Kragt, M. E., Ostermann, F. O., Pierce, S.A., \& Ramu, P. (2016). "Modelling with stakeholders-next generation". Environmental Modelling \& Software, 77, 196-220. 
Zykov, S. V. (2016). Crisis management for software development and knowledge transfer. Cham: Springer International Publishing.

Zykov S.V. "Crisis management for software development and knowledge transfer". Smart Innov. Syst. Technol. ISSN 2190-3018. 2016. Vol. 61.

Zykov, S. V., \& Gabeydulin, R. (2017). "The Global Crisis as Digital Transformation Motivator: from Lifecycle Optimization to Efficient Implementation Series". 23d Americas Conference on Information Systems, Boston, 2017. 